\title{
DECISION MAKING SOCIETY AND DECISION FORMING SOCIETY
}

\author{
Eizo Kinoshita \\ Meijo University \\ 4-3-3, Nijigaoka, Kani, Gifu 509-0261 Japan \\ kinoshit@urban.meijo-u.ac.jp \\ For Professor Thomas L. Saaty, with respect and admiration
}

\begin{abstract}
This paper explains the thoughts behind the mathematical model AHP. The AHP was specifically picked because, in addition to the fact that it is the mathematical model that describes the strategies in Sun-Tzu, it is a decision-moderating model and not a decision-making model nor a decision-forming mode. The author states in this paper that there are three different concepts -.. "make decision," "form decision," and "moderate decision" --- in decision making. If the Linear Programming can be called a decision-making model, then the AHP can be called a decision-moderating model. A decision-moderating model is a model that possesses both the feature of a decision-making model (the independence of the universal set of values) and the feature of a decision-forming model (the continuity with the people). Thus the AHP bridges together the independence and the agreement forming capability of the decision making process, and may well be the principle that governs the decision making processes in the twenty-first century.
\end{abstract}

\section{Introduction}

The author was quite impressed when he read $S u n-T z u$, the classic book on strategies. Especially, the phrase "If you know your enemy and yourself, you need not be wary of a hundred battles" is a truly knowledgeable and philosophical view.

The reason for saying this is because people often do not know themselves while spending a great deal of efforts in analyzing and understanding their enemies. Contrary to the general belief, it is possible that a person himself/herself is the one who knows least about himself/herself. As if to prove the point, Sun-Tzu follows the above phrase by, "If you know not your enemy but yourself, you will get a win for every loss. If you know not your enemy nor yourself, you shall imperil yourself in every battle." Even if people do not know their enemies but know themselves well enough, they can still bring it to a tie. However, it is affirmed that people are destined to lose if they do not know themselves. Strategies in a nation's military maneuvers and foreign policies, in business management, in an individual's life --- though all work on the different dimensions, all can be successful with the same principles. Insufficient information on the enemies and inappropriate analyses on one's self will almost certainly turn winnable games into losses. Even in professional baseball games, it is not a surprise to see a team with a lot of high profile players lose if the team's management (strategy and tactics) is neglected. 
Going back to Sun-Tzu, it is a well known fact that Takeda Shingen borrowed the four letters "wind," "forest," "fire," and "mountain" and made them the famous slogan for his army. When Oda Nobunaga defeated his arch enemy Imagawa Yoshimoto at the battle of Okehazama, he was leading a small army compared with that of Yoshimoto's. The battle is still a legend as it makes a typical example of a smaller army beating a larger one. Nobunaga made it the only objective to take Yoshimoto's life (strategy) in the battle, and implemented every possible operation to achieve the goal (tactics). It is believable that Nobunaga analyzed to the very end his lack of manpower (weakness). He followed the teachings of Sun$T z u$ and succeeded.

On the other hand, Germany and Japan who were defeated in the World War II were both led by a personality cult --- Germany by Hitler, and Japan by the Emperor (the two were not identical though, as Hitler exalted himself on his own power while the Emperor was set up in the position by the military leaders). Needless to say, but a self analysis is something a cult cannot do.

The opposing Allies, USA and Great Britain, maintained strategic perspectives and kept analyzing the enemies and themselves as $S u n-T z u$ had taught. Linear Programming was born as a byproduct of the process. First proposed by an English mathematician G. B. Dantzig, it is believed that the development of Linear Programming started as a project to find the most effective way to attack the German submarines. Later the project saw a huge progress when a solution to the Linear Programming --- the Simplex Method --- was invented. In a sense, the Simplex Method was the first of the mathematical model for the strategies of Sun-Tzu.

After the World War II, an ideological confrontation, the cold war, had started with the USSR and the USA at its center; at times, the tension went extremely high and the world was on the verge of a nuclear war. T. L. Saaty, who later proposed the AHP, was studying the OR (Operations Research) on strategies against Russia at the Pentagon at the time. He then moved on to the Department of State and studied the OR on the limitation of armaments as well as the disarmament. With these strategic operations in military and in foreign policies on its background, the AHP was born later. The author calls the AHP the second version of the mathematical model for the strategies of Sun-Tzu.

Like the Simplex Method in Linear Programming, a solution to the AHP was given as the Super-Matrix Method. With this solution, the study of the AHP made a quantum leap; so much so that Saaty himself named the model the Super-Matrix Method (or the ANP).

On the other side of the ocean, the USSR who had been the subject of study was forced to throw away the dogma of communism after the Berlin Wall had collapsed, and then transformed itself into the new Russia. Like the Germans under the leadership of Hitler, they made the mistake of not being capable of analyzing their own dogma. The cold war had ended with the USSR's loss. This also proves the correctness of the strategies in Sun-Tzu.

The writer of Sun-Tzu is believed to be Sun Wu who was a strategist during the Eastern Chou Dynasty in the old day China. In short, the book is about the optimum strategic theory, and discusses strategies in an entirely flexible manner. It must be noted that the book specifically warns against confusing strategy and tactics. According to the book, it is stupid to fight a battle after a battle even if an army could win them all. It insists that putting one's efforts solely on a mere display of combat skills is nothing but a nonsense. Fighting battles one after another itself proves that it is a struggle without a strategy, and any strategist with a sense of mind must try to find a way to avoid battles other than the final and the decisive one. When the time has come for the decisive battle, one must make good use of all the cards he/she owns under the utmost concentration of the will power as well as the physical power. In other words, if you build a database on your enemy and on yourself, and analyze it using the AHP (and other methods), then you need not be wary of a hundred battles.

Incidentally, as we face the twenty-first century, the world is looking for a new order. Thus the concept of "decision making" has become more important than ever. If the AHP were to be of help to those who need to make decisions, there will be nothing more to make the author happier. 


\section{Decision Making Theory}

One faces a variety of problems, as expected, in the process of being adopted into the society. Which college to attend, which business to go into after the graduation, who would be the Mr./Mrs. Right, which location to choose when buying a house --- these are only a few of those problems. In all of the cases, a person would choose one or more solution(s) among many options available based on some criteria.

In this perspective, living can be described as a series of selective behavior. In a sense, one's life is a result of the sum of his or her decision makings. In addition, those decisions are often made based on one's own subjective perception of the complicated and obscure circumstances.

On the political and economic scenes, the modern era is truly a time of turbulence. The year 1989 signifies this fact. On November 9, 1989, the Berlin Wall collapsed and the East-West relationship turned from Yalta to Malta. Since then, the storm of reformation had blown throughout the eastern world and had landed in the former USSR which collapsed in December 1991. As a result, we are all looking out to see the formation of the new world order.

On the other hand, the global environmental issues were brought up in the 1989 Summit meeting, which forced the nations around the world to change and look at things from the global perspective. The overall system has grown so big and beyond the borders, that it is no longer adequate to consider the environment, the economy, and the society within a nation alone.

In Japan, on December 29, 1989, the Nikkei-Dow average of the stock exchange market reached 39,000 yen (the total market value of 530 trillion yen - approximately 4 trillion dollars). It was the pinnacle of the so-called "bubble economy." The "bubble" had eventually popped and the stock market bottomed out at around 14,000 yen (the total market value of 230 trillion yen - August 1992 and June 1995). Although the stock market has since been slightly better, the scars caused by the composite depression were deep; in the macroeconomic terms, the financial crisis (triggered by the slumping prices of real estates) continued, and resulted in the low plant investment, the low consumption, and the low rate of growth in the GNP.

The financial crisis was especially serious, starting with bankruptcies of credit unions, to the ultimate repulsion by the people against the government aid to the housing-loan companies (Jyu-sen) that went bankrupt. The series of events depicted the foolishness of the people who had ridden high on the "bubble" and had gone despair as it popped.

On the microeconomic sides, the recession caused low disposable income through reduced overtime work, and then overall reduction in employment among which the middle-management class was hit the hardest. It is the sign that the time has come for the Japanese to reconsider their high degree of loyalty to their employers, as the loyalty has been maintained by the conventional lifetime-employment and the seniority system. It indicates that a person is now asked to be a better citizen than being a better employee, and to turn his/her eyes on achieving higher quality of life (a consumer-oriented society) by alternating to the qualitative way of thinking from the quantitative way of thinking.

So far, we have seen that the year 1989 was the turning point from the three perspectives (the fall of the Berlin Wall, the global environmental problem, and the end of the Japanese "bubble economy"). The Japanese domestic politics has been experiencing changes since then.

First, through the crisis in the Middle East and the civil war in Cambodia, Japan was asked for financial contributions to the allied forces and to send its troops overseas. This involves a new interpretation of the Constitution as well as decision-making of Japan as a nation and complicates the situation. 
Second, there are problems of the political reform and the reconstruction of political parties. It started as a reformation of the election system and the political fund raising system, but later led to the collapse of majority ruling by the LDP (Liberal Democratic Party). It marked the end of so-called the 1955-Regime and, for the first time in forty years, the government was run by non-LDP powers. We even saw a Copernican change in the Japanese politics --- the birth of a socialist prime minister under the coalition between the LDP, the Japan Socialist Party, and the Shinto-Sakigake (the Harbinger Party).

Third, there is the problem of strengthening the national crisis management system in terms of urban security and disaster prevention that has been brought up through the Hanshin Earthquake and the sarin attack on Tokyo subway in the early 1995 . Japan had long been said not being apprehensive of national crisis and, at last, its poor crisis management capability was exposed that year.

Even the government aid to the housing-loan companies mentioned before needs to be perceived as a matter of crisis management in terms of disposal of bad credits in the monetary system after the collapse of the "bubble economy." Sensing the currents of the time both domestically and internationally and making the right decisions is the priority for Japan now.

Incidentally, Japan has experienced such drastic shifts in currents at least three times in its history: first from the Sengoku Period (Warring State Period) till the establishment of the Tokugawa shogunate, then the end of the Tokugawa shogunate and the Meiji Restoration, and when Japan was defeated in the World War II.

The administration of the Tokugawa shogunate put its priority in the unification and stabilization of Japan, thus shutting down the flow of information by the National Seclusion which effectively prevented colonization of Japan by the foreign powers. To the author, though not well informed of historians' views, it seems that Tokugawa Ieyasu and Tokugawa Iemitsu made important decisions and achieved what Oda Nobunaga and Toyotomi Hideyoshi had been unable to.

The second crisis started as Commodore M.C. Perry and his fleet of "black ships" arrived Japan and lasted until the establishment of the Meiji Administration, during which numbers of decision makers participated in making the history. This period is characterized by the fact that completely different group of decision makers contributed to end the shogunate and to start the Meiji era. Nevertheless, the change in personnel had been smooth and the modernization of the Japanese society was a success. On the afterthoughts, those people must have made the right decisions.

At the end of the World War II, we saw the catastrophe of the Empire of Japan. As a consequence, the former decision makers were forced out and the reform took place by the manuals made by the GHQ (or by General Douglas MacArthur). Thus there was no true (Japanese) decision maker at the time. This reform set the footage for the recent economic prosperity including the unprecedented rapid growth of Japanese economy.

However, it must be noted that the absence of the true decision maker left a huge debt on the Japanese which has to be paid back. That repayment is a process of maximum adaptation under the various conditions described before, and its degree of difficulty certainly exceeds that of decisions made by Ieyasu or during the Meiji Restoration.

Difficult, that is, unless one remembers the phrase "If you know your enemy and yourself, you need not be wary of a hundred battles" from $S u n-T z u$, the classic book on strategies. One must also remember the following three key-words about the current age; diversification, fuzziness (as in fuzzy logic), and sensibility (richness and ease of mind). Raising one's consciousness in this paradigm requires, as stated before, conversion from the quantitative set of values to the qualitative set of values. 
It must also be pointed out that, to develop arguments under the new circumstances aforementioned, we need the problem-solving type of arguments, not the accusation type of arguments to attack some scapegoat, nor a criticism that simply handles the phenomenal aspects. In this sense, we can benefit largely from the school of thoughts in management science. The O.R. (Operations Research) and the Decision Making Theory are the mathematical methods which have their roots in management science.

We may say, "If you build a database on your enemy and on yourself, and make analyses using the O.R. or decision making models, you need not be wary of a hundred battles." In other words, nations, districts, enterprises, and individuals can, despite the differences in their sizes, all solve their problems by applying management-scientific analyses. It is conceivable that the concept of "management science" will be the key-word to find solutions in important;issues in the nineties, and well into the twenty-first century.

It is considered that there are two aspects in management science; one is decision making and the other is problem solving. Therefore, it is important to clarify the relationship between these two concepts.

First, the decision making process is a series of actions which includes defining the problem (clearly state the objectives or goals), identifying the alternatives (select the plans to achieve the objectives), determining the criteria (determine the criteria used to evaluate multi-purpose plans), evaluating the alternatives (evaluate each alternative plan on each criterion), and choosing an alternative (based on the total evaluation of every alternative, pick up the most feasible one).

The problem solving process and two more additional steps: implementing the decision (carry out the plan and work on the details if necessary), and evaluating the results (as a result of picking the most feasible alternative, evaluate if the problem has been solved). Figure-1 shows these relationships.

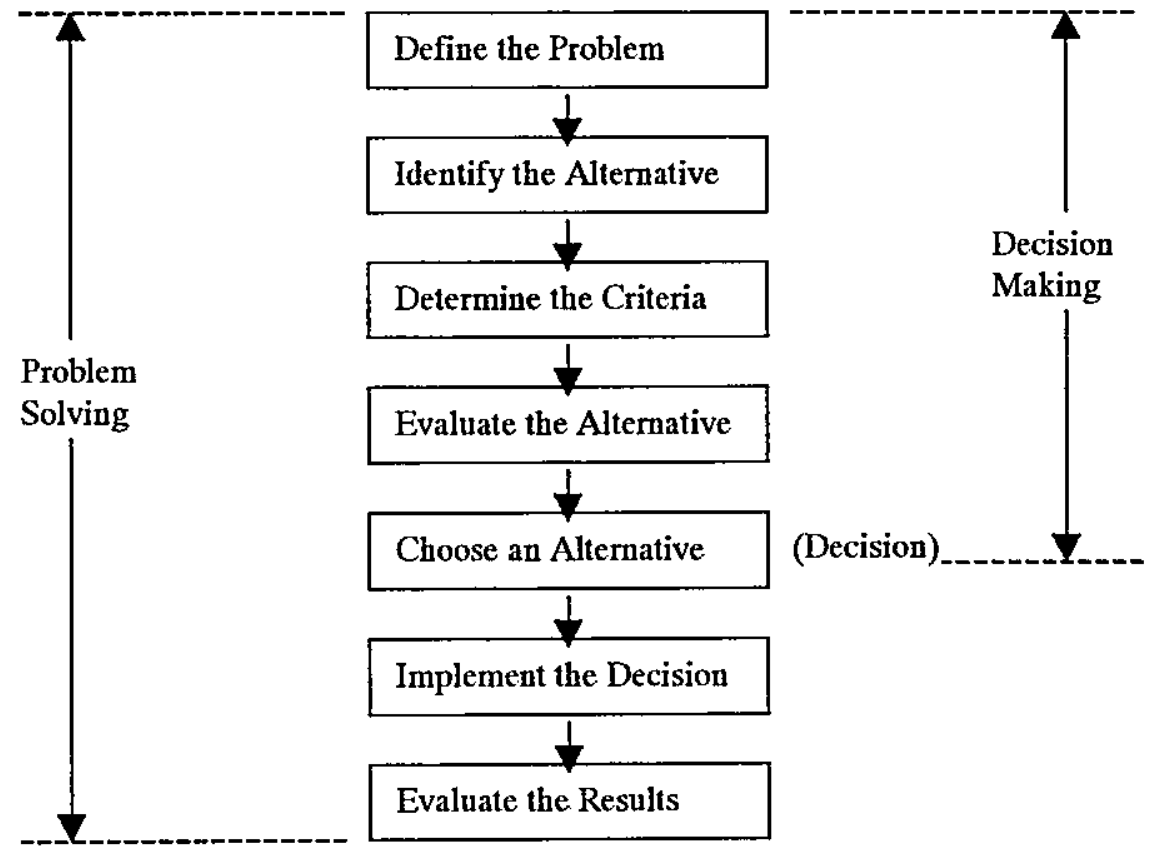

Figure-1: The Relationship Between Problem Solving and Decision Making 
The decision making process can be sub-divided into two steps: the first step is called "structuring the problem," and the second is called "analyzing the problem." Here, "structuring the problem" includes defining the problem, identifying the alternatives, and determining the criteria while "analyzing the problem" includes evaluating the alternative and choosing an alternative.

Furthermore, the step of "analyzing the problem" can be categorized into two, depending on the contents of data. One is the "qualitative analysis" which handles qualitative data, and the other is the "quantitative analysis" which handles quantitative data. Figure-2 summarizes these relationships.

In the past, various methods have been devised to help solving these decision making problems. Among them, the most well-known is the Linear Programming (which depicts various problems using straight lines and solve them). This method is the typical model for the problems that can be solved using quantitative information: the problems that have well-defined structure, and whose quantitative relationships are clear.

Structuring the Problem

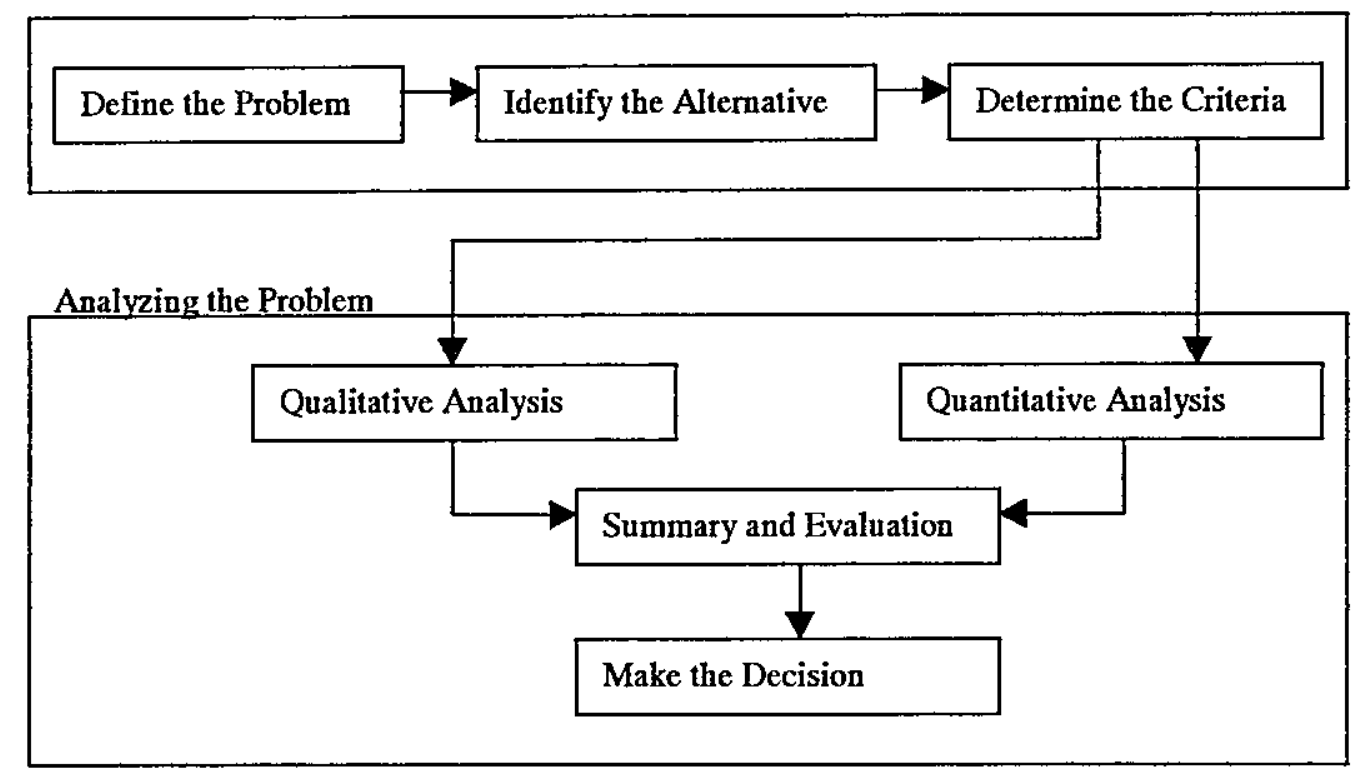

Figure-2: Structuring the Problem and Analyzing the Problem

However, there are some short-comings in these conventional models (e.g. Linear Programming). First, they can only handle problems with single objective and, second, they cannot process qualitative information. In order to solve the former, we need an alternative method that can pursue multiple objectives, i.e. a multi-purpose decision making model. To solve the latter, we need to find a method (model) that can process qualitative information. This is a problem solving model that can handle people's feelings, intuition, or some vague circumstances. On the background, there is the increasing demand in recent years for making judgements based on qualitative information. 
These are the characteristics of mathematical models that future management science must provide. The AHP model is the one that brings solution to these requirements.

The author stated before that management science was made up of decision making and problem solving. One can see the concept of management strategy summarizes these two. The strategic behavior (conception) forms the cycle of "Target - Plan - Do - See" as shown in Figure-3.

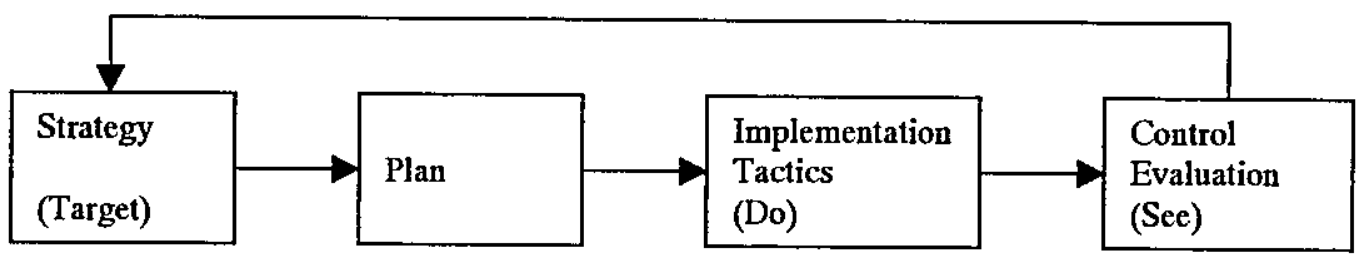

Figure-3: Strategic Behavior

Strategy is another word for the objectives (targets) of one's behavior --- it can also be described as the ideal form or the vision. After the strategy is set, action plan will be devised on it. Next comes the actual implementation of the plan. Finally, after the implementation is completed, evaluation of the outcome must be done to control the whole process. This complete process is called the strategic behavior.

When one cycle is completed, a new strategy (target) should be born as a result of evaluation. When this happens, there will be an additional arrow from the control/evaluation (See) stage to the starting point, which completes the feed-back system. In the following chapter, the author will dig deep into the concept of decision making.

\section{Make Decision, Moderate Decision, and Form Decision}

In the previous chapter, the author defined the process of decision making. Here in this chapter, he will put a light on how it is done --- the inner mechanism of decision making.

In a family, a father who is concerned about disciplining his son ordered: "When you come home, after taking them off ${ }^{(1)}$ you should put your shoes in place." Despite his effort to repeat the order day in and day out, his son paid no attention to what was told.

One day, the father had enough and consulted his wife what to do. "Our son shows no improvement in his manners. Maybe we should use physical pains (by šlapping) so he would remember. What do you say?" But the mother was against it, saying, "We better wait till he decides he will listen. He would only repel if he felt he was being forced to do so." The father was convinced. Only this time, his wife cooperated in telling the son that a person with good manners would be respected, or that he would improve his fortune, and so on. Those words continued to float in the air as if they were a BGM. But to no avail, the boy's manners did not improve. 
Then, a neighbor who had heard the story offered an advise to the son; "You see, when you come home, you take off your shoes at the entrance, and put them r-r-r-right here!" As he was saying, he drew on the floor two foot-prints with a chalk. The boy seemed to like the foot-prints and started to put his shoes in their places. Even when the foot-prints were gone, his behavior did not change. This experience gave him the taste (of jubilant responses from his parents) and he became more interested in the other areas of his manners which he improved dramatically.

From the above story, the author proposes the concept of decision making to be as follows; that a decision making involves the field in which the decision will take effect, and an institution which is responsible for the decision making (Figure-4). In the above example, the only member in the field is the boy and the decision making institution is his father (or the neighbor).

It is possible to have multiple number of members and, in some cases, the members in the field may also be the members in the decision making institution. As for the members within the institution, they may not necessarily be humans. They can be substituted for by fortune-telling, mathematical methods, a computer system, or by the God.

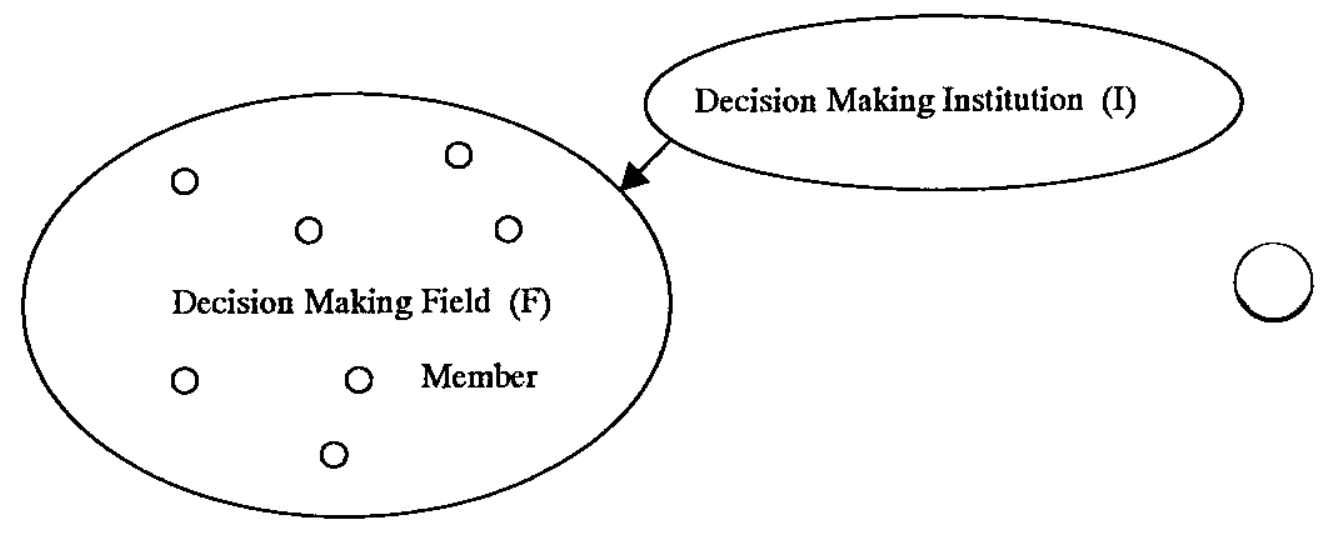

Figure-4: The Concept of Decision Making

Even when the field and the institution have common members, it is necessary to maintain the independence of the decision making institution from the field in one way or another. From here onward, the letter $\mathbf{I}$ is used for the decision making institution, and $\mathbf{F}$ for the field.

Going back to the example, when the father ordered his son "When you come home, you should put your shoes in place after taking them off," the father's behavior displayed the concept of "making decision." In this case, note that the $I$ (the father) and $\mathbf{F}$ (the son) are independent of each other as mentioned before.

Next, had the mother's idea worked and the boy decided to put his shoes in place on his own, the concept is called "forming decision." Further, when the boy followed the advise of the neighbor, the neighbor had displayed the concept of "moderating decision." 
Now, Figure-5 summarizes the three concepts of "make decision," "moderate decision," and "form decision." Let's first take a look at Figure-5A. Here, "make decision" and "moderate decision" are grouped together; both of them are transitive verbs, and there is a decision maker (I) who is independent from the field of decision making (F). On the other hand, "form decision" is an intransitive verb ${ }^{(2)}$ and that indicates the fact that I is either non-existent (i.e. the same as F) or, if it does exist, subsidiary to F.

Next, in Figure-5B, "moderate decision" and "form decision" are grouped together. Here, it indicates that the moderator (I) and the field (F) are continuous even when moderating a decision. It must be noted that, in case of forming a decision, $\mathbf{I}$ is the same as $\mathbf{F}$ or subsidiary to $\mathbf{F}$ and thus $\mathbf{I}$ and $\mathbf{F}$ are continuous in their nature.

In the example, if the boy made his own decision to improve his manners, an independent decision maker (I) is either non-existent or, if it does exist, subsidiary to F (the parents may be considered as I, but by merely suggesting various merits of being good-mannered, they do not exercise the ultimate power and thus they are subsidiary to the boy). Another way to put it is: I and $F$ are either the same or continuous.

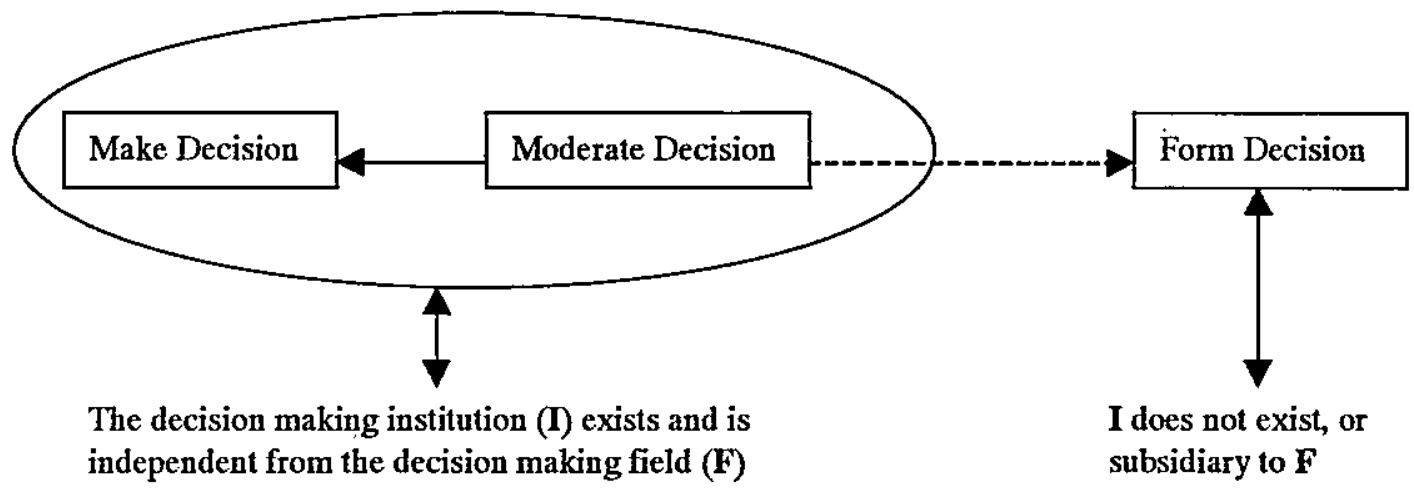

A. independent from the decision making field (F) subsidiary to $\mathbf{F}$

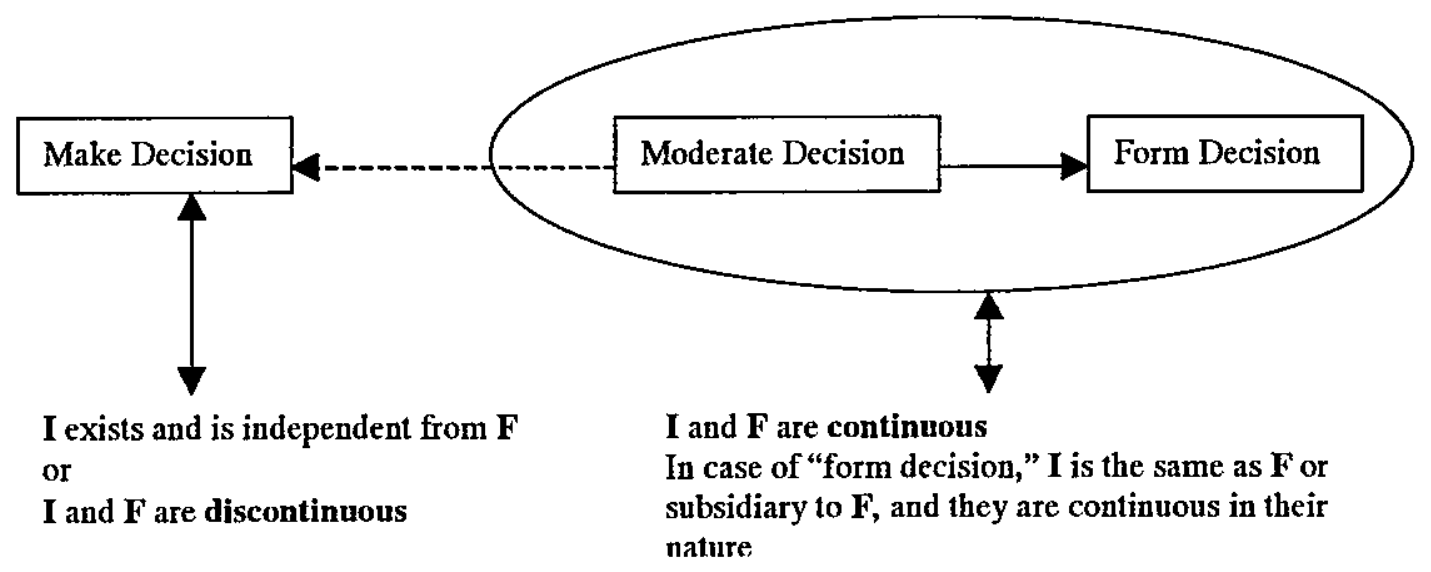

Figure-5: Make Decision, Moderate Decision, and Form Decision 
The example of moderating a decision can be explained as follows. By the action of the neighbor who drew the foot-prints on the floor of the entrance, there was a hearty communication (an exchange of information) between the neighbor (I) and the boy (F) and the boy's new behavior of improving his manners was determined.

On the other hand, in making a decision, the decision maker (I) and the field where the decision take effects (F) are discontinuous; in the above example, the decision was simply conveyed to the son in the form of father's order.

As shown in Figure-5, we consider that "make decision" and "form decision" sit at the opposite ends, and "moderate decision" sits somewhere in the middle. When the gravity of "make decision" is strong (when the existence of an independent I is emphasized), "moderate decision" would be pulled towards the left (Figure-5A), and when the gravity of "form decision" is stronger (when the emphasis is on the continuity of $I$ and $F$ ), it would be pulled towards the right (Figure-5B).

Next, the author would like to study another example. The followings are from the postscript.-- The Dying Voice --- in The Japanese and the Jews written by Hichihei Yamamoto.

The last words of Hamlet was "He [Fortinbras] has my dying voice (Shakespeare 202)." It was a matter of fact that, in a kingdom, the son would succeed when the king had died. However, by the rule, a king was supposed to be elected, which was why Hamlet needed to express his support. On the other hand, things are opposite in Japan; Hideyoshi did not succeed the post of Kanpaku (imperial regent) but he had won it with his own power. Nevertheless, an arrangement was made so it looked as if Hideyoshi had succeeded the post. No matter what, ... winning it all strictly by power without having a proper family background was not good enough --. as if it were a gold-plating only on the surface. (Yamamoto)

Further, Yamamoto continues:

In one society, one succeeds a kingdom but disguises it in an election. In an another, one takes over the country with his power (in a sense, it is an election without voting) but pretends as if he would have been meant to because of his family line. (Yamamoto)

The last paragraph is most important. Using the concepts in Figure-5, we can explain the behavior of "one succeeds a kingdom but disguises it in an election" as follows: in actuality, the family background is the decisive factor, which means there is no independent decision making institution. However, in a society where that is inappropriate, people will declare the existence of such an institution (an election in this example). By doing só, the appearance has shifted from forming a decision to making a decision (Figure-5).

Likewise, the behavior of "one takes over the country with his power but pretends as if he had been meant to because of his family line" can be explained as follows: the decisive factor here is warfare (an election without voting) among the lords, which means the decision making institution (the decision maker, $l$ ) and the decision making field (where the decision takes effect, F) is discontinuous. However, in a society where that is inappropriate, people make it known, on the surface, that $I$ and $F$ are continuous (the concept has shifted from making a decision to forming a decision on Figure-5).

Thus, if we follow the concepts of decision making presented in this paper, the Jewish-Christian society Yamamoto describes is the society in which an independent decision making institution is necessary. On the other hand, the Japanese society he describes is the society in which $I$ and $F$ have to be continuous.

The author does not necessarily believe in the statements that the Jewish-Christian society is entirely a decision-making society and the Japanese society is entirely a decision-forming society. It is possible that, under various circumstances, the weight may sway between the two. 
The author does maintain that there exist decision-making societies as well as decision-forming societies, and distinction between the two rests on the degree of necessity for independent decision making institutions, and on the degree of continuity between the decision maker and the field in which the decision takes effect.

Incidentally, the two characteristics these societies have are also the two significant perspectives one must possess at every decision making situation.

In a decision-making society, the existence of independent decision making institutions is emphasized and the continuity between the decision maker and the field is neglected. The last words of Hamlet proclaims the necessity of the election which is an independent decision making institution. In his society, people must make decisions and absolutely must avoid forming decisions.

On the other end, in a decision-forming society, the perspective is on the continuity of the decision maker and the field, and no consideration is given to the necessity of independent decision making institutions. Therefore, when Hideyoshi succeeded, on the surface, the post of Kanpaku, he definitely proclaimed the continuity between the decision maker and the field. In this society, people absolutely must avoid making decisions but must form decision.

The ideal way of finalizing a decision must satisfy both of these characteristics (perspectives) at the same time. By having an independent decision making institution, we can eliminate the possibility of closeddoor arrangements among the people who are the most affected by the decision. Hence, the system displays the righteousness and the independence of the decision making. Further, it is easy to logically explain the process of decision making and thus reproducibility (being able to reproduce the current status as reference if needed) is secured.

The continuity between the decision maker and the field, on the other hand, guarantees the agreements by the affected people with the decisions made. If an administration wants to build a public facility like an airport or a road, but single-mindedly forces its decision to the residents, it is conceivable that the residents would protest. In such cases, obtaining the agreements from the people (i.e. the residents and the taxpayers) will be extremely important; it will promote mutual trust and a sense of responsibility on the residents' side. The responsibility mentioned here is the kind that the resident feel obliged to protect the project, which is significant in reducing the risks. In this meaning, a decision-forming society is a society that tries to avoid the risks arising from conflicts.

When one pursues the best way of decision making, it becomes necessary to, as stated before, satisfy the two conditions simultaneously: the independence and the agreement-forming capability of the decision making process. This will throw anybody into a dilemma. If one makes a decision to maintain the independence of decision making, it may hurt any other effort made to form an agreement whereas, if one tries to form a decision so an agreement be reached with the members.in the field, the independence of the decision making process will not be maintained.

Therefore, the author hereby proposes the concept of moderating decisions as the ideal way of decision making. This concept will satisfy the independence of the decision making process and still offers the capability to form an agreement within the field. In other words, it is possible to have an independent decision making institution while maintaining the continuity between that institution and the field of decision making. The decision making of the future should be done based on the concept of moderating decisions introduced in this paper.

Now, in the following chapter, the author would like to explore two different societies that embrace the concepts of making decisions and forming decisions which are both introduced in this chapter (Figure-5), i.e. a decision-making society and a decision-forming society. 


\section{Decision-making Society and Decision-forming Society}

In the previous chapter, we have defined the three new concepts: make decision, moderate decision, and form decision. Here, if a society puts a strong emphasis on making decisions and if the concept of moderating decisions, which sits in between the two opposite concepts (making decisions and forming decisions), is gravitated towards making decisions, we call this society a "decision-making society" (Figure-5A). The characteristic of this society is the existence of independent decision making institutions; the society is built around the axis of the independence of decision making.

Opposite to this is a "decision-forming society" in which moderating decisions is gravitated towards forming decisions (Figure-5B). The characteristic of this society is in the continuity between the decision makers and the fields of decision making; the society is built around the axis of the agreement forming capability of decision making.

Now, in this chapter, four different aspects of these two societies will be discussed.

\section{4-1. Gods (The Absolute God and Multiple Gods)}

The concept of god exists throughout the world, in every ethnic group and in every society. But the concept may not be exactly the same; in fact, there is a fundamental difference between the concept of god in a decision-making society and that of a decision-forming society.

The God in a decision-making society is the absolute and the only being. the existence of its own and the creator who, with His purpose, made the universe and decided how everything worked. Hence, He is discontinuous from humans within the decision making field. In the eyes of a human, He seems somewhat reserved. The relationship between the God and the human being is analogous to that of a father and an adopted child --- there is no blood relationship but only a contract.

Suppose there are two men, A and B, who make some promise between them. Here, the promise is not only a matter between the two who are both in the decision making field, but also something to do with the God who has a capacity to act as an independent decision making institution. When $A$ and $B$ make their promises, they also sign a contract with the God. As a result, the simple promise between the two can also be interpreted as a contract with the God working as a go-between. Therefore, if A does not keep his promise, it is not only a betrayal to B, but also a betrayal (a blasphemy) to the God. Then it is possible to conceive the idea of the God's punishment (Figure-6). 


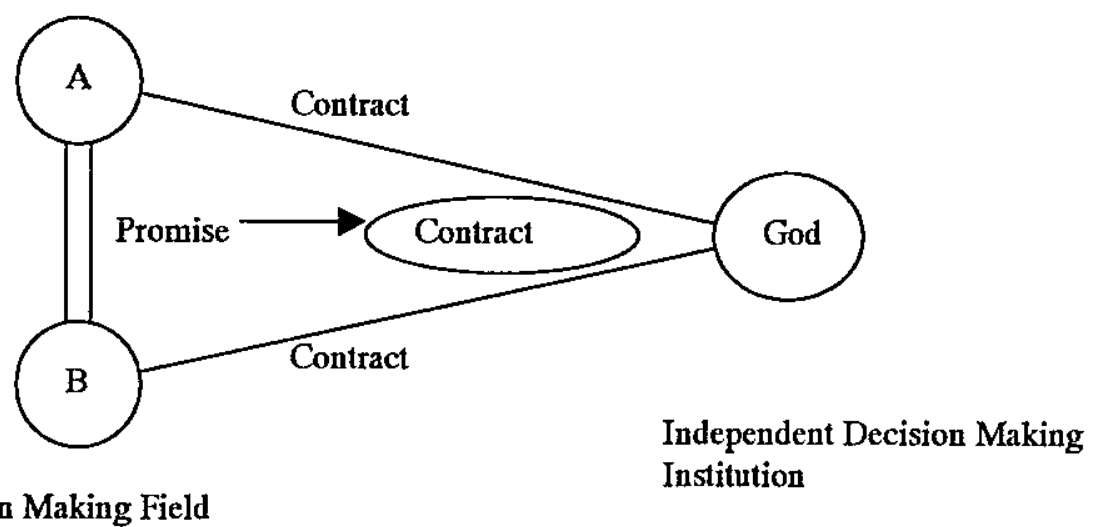

Decision Making Field

Figure-6: The Absolute God

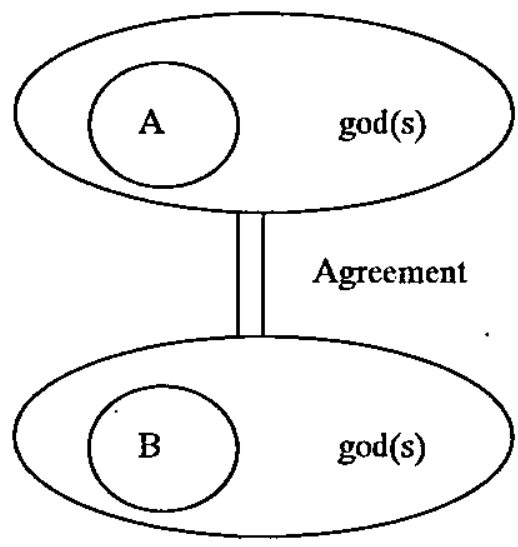

Figure-7: Multiple Gods

Decision Making Field

On the other hand, the god in a decision-forming society is an existence dependent on humans (or, exists within the minds of humans). Therefore, the god is continuous with the humans in the field of decision making and is a "human-like" being. In analogy, there is a blood relationship between the god and humans. And there does not exist a concept of a contract between the god and a human.

If the two men, $A$ and $B$, are living in this society, the promise will not be a contract but merely a honest talk or a gentleman's agreement. In a sense, the god can be interpreted by each man in any way he wants. Furthermore, gods can be found everywhere since there is no such thing as the absolute and the only God. Gods can be found in the nature (e.g. in the mountains, rivers, seas, and on rocks), in buildings, and even within objects. Thus, people will not talk about receiving the God's punishment but about receiving a retribution --- an expression quite human-like. (Figure-7) 


\section{4-2. Common Sense and Public Image}

In every ethnic group and in every community, there is a set of values that provides basis for the principles of the people within. Now, let's consider how people's principles (set of values) are formed in a decision-making society and in a decision-forming society.

In a decision-making society, people's principles are made based on a standard value (e.g. the common sense) that is independent from the community in which those people live. In our discussion, such a community will be called a "society."

In a decision-forming society, on the other hand, people's principles are made based on a standard value (e.g. a public image) which exists within the community itself. And such a community is called the "public": the public as in the public image, the public belief, the public eye, etc.

Thus, in a "society," the standard value is discontinuous from the people within the community. When one displays an antisocial behavior, he/she must feel a guilt of some sort. Note that the guilt mentioned here does not involve the law. It is the guilt as punishment as he/she has faulted the standard value which is independent from the community. If the standard value is the words of the absolute God described in 4-1, then it is the guilt as the God's punishment.

In the "public," however, the standard value is continuous with the people in the community. If one displays an anti-public behavior, he must feel a shame of some sort. Feeling the shame is the kind of punishment from the public, as his/her behavior is against the standard value that lies within the community.

In this sense, the author agrees with Ruth Benedict, an American anthropologist, who has given us an unique insight in her work The Chrysanthemum and the Sword.

She states: "In anthropological studies on different cultures the distinction between those which rely heavily on shame and those that rely heavily on guilt is an important one (Benedict 222)."

Incidentally, the concepts of "guilt" in decision-making society and "shame" in decision-forming society do not necessarily coincide with what Benedict describes. Nevertheless, the author selects these words with due respect to Benedict's work.

What has been discussed in this section can be summarized as follows. In a "society," community's principles are based on an independent set of values and, when those principles are violated, a feeling of guilt will be forced upon the violator as a punishment which is discontinuous from the community. Note that the structure is similar to that of the decision making institution and the field in a decision-making society. On the other hand, in the "public," community's principles are based on a set of values within the community and, if they are violated, a feeling of shame will be forced upon the violator as a punishment which is continuous with the community. Note that this structure is similar to the institutionfield structure in a decision-forming society (Figure-8). 

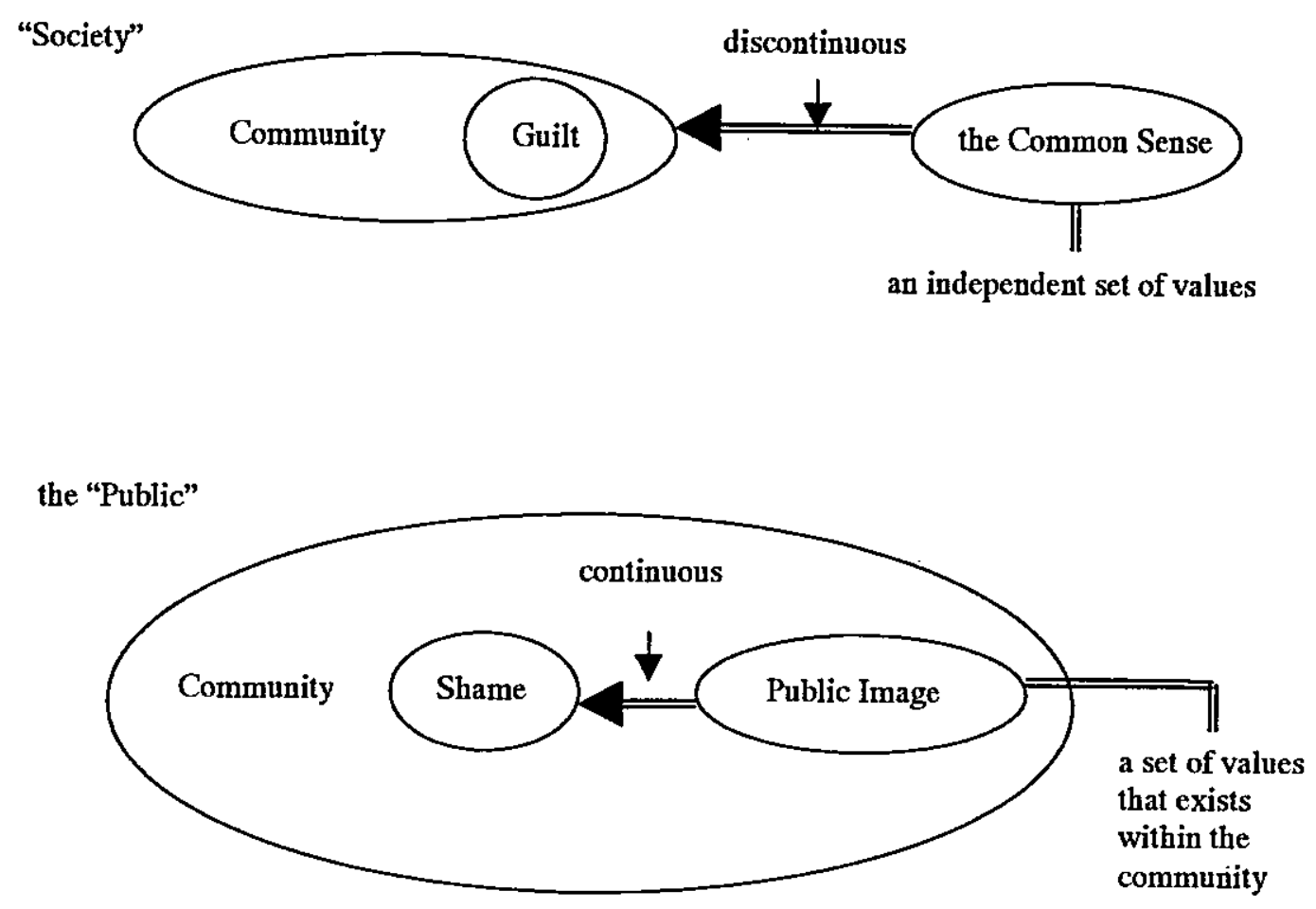

Figure-8: The "Society and The "Public"

\section{4-3. Invalid Unanimous Decision and the Law Outside the Law}

In the previous section, a "society" and the "public" were defined. To further explain these concepts, the author would like to quote two examples from The Japanese and the Jews. In this book, Yamamoto states that there was an institution called Sanhedrin in the Jewish society (around the time of Christ), and it was something like the Diet and the Supreme Court. Sanhedrin had an explicit rule which read "An unanimous decision shall be considered invalid."

Yamamoto explains the reason behind the rule as follows:

... if the decision was a rightful one, there should have been ones against it. Unanimous decision was unthinkable unless it was a result of a bias, a mass excitement, or a pressure by a third party. That was why they thought the decision must be nullified...

Yamamoto continues further:

In Japan, it is considered that an "unanimous decision with no vote against it," itself proves the righteousness of the decision. Sometimes, people try very hard to render an unanimous decision even if a few oppositions would exist ... (Yamamoto) 
This is the important point. One society proclaims an unanimous decision is invalid because, if everybody thinks something is right, then there is a possibility that everybody is wrong. In another, people try to make an unanimous decision even if opposing opinions would exist. This statement accurately describes the differences in decision making in a "society" and in the "public."

It has already been stated in a "society," community's principles are determined based on a set of values which is independent from the community. Therefore, if there is an unanimous decision as a result of a bias, a mass excitement, or a pressure from outside, there is no way of monitoring the outcome of the decision. The reason is because the standard values and the outcome are discontinuous. Thus it is conceivable that the Sanhedrin rule was made to avoid the possibility of everybody being wrong. A "society," which is a decision-making society, also puts emphasis on the independence of the universal values from the community.

It has also been stated that, in the "public," community's principles are determined based on a set of values that lies within the community. Since the standard values and the outcome are continuous, people try to force an unanimous decision even if there are opposition. In the "public," which is a decisionforming society, put its priorities on the continuity between its standard values and the outcome. What the "public" wants to accomplish in a decision making process is forming an agreement.

As a "society" has a safety valve which is the Sanhedrin rule explained before, the "public" has similar institution "the law outside the law" which will be described next. The author will again quote from The Japanese and the Jews:

... In Japan, there is a solemn principle that says "People may not be bound by a decision to the one hundred percent." Right after the war, a judge made a news when he died of hunger because he refused to buy foods in the underground market which was illegal. This implies, of course, that he was the only exception. Other judges, members of the Diet who made the law, and the people who elected those members, all were not bound by the law ...

... Even an unanimous decision does not completely bind people including the voters themselves. ... Nobody really voice an opposing opinion against a law which guarantees one's death if he/she obeys. The ones who obeys the law will make the news but those who disobeys will be left alone. However, this does not mean Japan is in the state of anarchy. There is Japan's own "the law outside the law"...

... The law which brings death to people does not practically exist because it will be unconstitutional the moment every citizen thinks "such an inhuman law needs not be followed." (Yamamoto)

i.e. the "public" will forgive those who have violated the law. But "... the law does exist in the area that does not violate the right to live and, within that area, an offender will be punished (Yamamoto)." In this case, the "public" will not forgive him. In short, the law outside the law presented by Yamamoto is the "public" having the power to decide who should be accused.

\section{4-4. Mathematics and Arithmetic}

In this section, a comparative discussion of a decision-making society and a decision-forming society will be made from the perspectives of mathematics and arithmetic.

The author and his family stayed in Pittsburgh, USA, from June to October of 1991. During the stay, two daughters joined the summer school program operated by the city and in the fall, the elder daughter attended a local elementary school. Although they were perplexed at the school life in a new county, they got extra high marks in arithmetic. According the elder daughter (in the fourth grade), what they were learning in the class was that she had already learned when she was a third grader in Japan. Even so, her classmates were having difficulties. This episode confirms that the arithmetic ability of the Japanese children is indeed very high. 
This took the attention of the author to speculate on the cultural factors why the Japanese are so good in arithmetic. First, the Japanese have inherited an agricultural gene and, because of this, hard work has been the virtue and the social code ("the public code" may be more accurate expression).

Second, the Japanese common people bave developed the $k u k u$ song ${ }^{(3)}$ to memorize multiplication and an arithmetic machine like abacus.

Third, the Japanese language constructs numbers in decimal system. This makes a stark contrast with the English language, for example, which uses the duodecimal system and has distinct names for numbers up to 12. Similarly, the German language also uses the duodecimal system and $\mathbf{1 3}$ is the first number expressed as 3 and 10. The French language, however, uses the system of base 60 . The number 70 is expressed as 60 and 10 and 71 as 60 and 11. Making things complicated in French is the fact that 80 is expressed as 4 times 20,81 as 4 times 20 plus 1 , and 90 as 4 times 20 plus 10 . It is easy to believe that the Japanese language's decimal system is advantageous in learning arithmetic.

However, when it comes to mathematics, these factors do not necessarily work for the Japanese. For example, it is said that a race with stock-farming genes possesses excellent instinctive faculties (creative intuition). The lack of the kuku song and arithmetic machines may encourage people to understand basic mathematical principles. Furthermore, by studying mathematics using the duodecimal system or the base 60 system, it is possible to get insights on the overall mathematical structures.

The above statements (or rather, the reverse of them) unexpectedly reveal the Achilles' heel of Japan which has long been described as a technology power and a minor science power.

Next, the relationships between mathematics (i.e. science) and arithmetic (i.e. technology) will be discussed from the perspectives of decision-making society and decision-forming society introduced in this paper.

As stated before, a "society" which is a decision-making society requires an universal set of values that is independent from the community. Mathematics (science) offers one more alternative for such a set of values. Mathematics describes the natural phenomena (and some portion of social phenomena as well), and has nothing to do with the members of a community (discontinuous). Hence it cannot be helped that mathematics is difficult to be handled and hard to be applied for any human being. It is easier for the people in a decision-making society to develop mathematics (and science) as they must have such an universal set of values.

On the other end, a decision-forming society, or the "public," is defined as the one that requires the set of values to be within the community. One of such values is arithmetic (technology). Arithmetic must be used in everyday life, and thus is continuous with the people. Hence, it becomes easy for the people to handle and apply. The reason why arithmetic (technology) is emphasized and mathematics (science) is not in a decision-forming society is because its people put priority on the continuity of their values and themselves.

So far we have discussed the concepts of decision-making society and decision-forming society (i.e. a "society" and the "public") from four different perspectives. It is now understood that the characteristics of a decision-making society is in the existence of an independent set of values, and that of a decisionforming society is in the existence of a set of values that is continuous with the people.

The ideal society of the future, however, needs to have those two characteristics simultaneously. In other words, the society with an independent set of values which makes it possible to seek the universal truth, and also with a continuous set of values which makes it possible to seek the ease and convenience of technologies. We will call such a society a decision-moderating society (which satisfies both the independence and the continuity of its set of values). 
When one views a decision-making society from the stand point of decision making process, the independent set of values is the decision making theory such as the OR (i.e. Linear Programming, the Game Theory, the Optimization Method, etc.). When one views a decision-forming society from the same stand point, the continuous set of values is the method that does not require mathematics: subjective judgement, the sixth-sense, etc. And when one views a decision-moderating society from the same stand point, the independent yet continuous set of values is the new decision making theory --- the AHP.

To put it in the other way; a decision-moderating society will be the bridge between a decision-making society (similar to the Gesellschaft) and a decision-forming society (similar to the Gemeinschaft), and the AHP (a new decision making theory) will be the bridge between the independent set of values and the continuous set of values.

To conclude this paper, the author would like to point out that the Jewish-Christian society is not necessarily be the decision-making society described in this paper and, likewise, the Japanese society is not necessarily be the decision-forming society. 


\section{Bibliography}

[1] Kinoshita, E.: SonShi no Heihou no Suugaku Model (The Mathematic Models for Strategies of Sun-Tzu). Tokyo: Kodan-Sya, 1998.

[2] Kinoshita, E.: SonShi no Heihou no Suugaku Model, JissenHen (The Mathematic Models for Strategies of Sun-Tzu, Implementation). Tokyo: Koudan-Sya, 1998.

[3] Yamamoto, Hichihei: Nippon-Jin to Yudaya-Jin (The Japanese and The Jews). Tokyo: Kadokawa- Syoten, 1971.

[4] Kinoshita, E.: Management Science Nyuumon (Introduction to Management Science). Tokyo: Kindai-Kagaku-Sya, 1996.

[5] Benedict, Ruth:The Chrysanthemum and the Sword. Tokyo:

Charles E. Tuttle Company, 1954.

[6] Shakespeare, William: Hamlet. London: Penguin Books Ltd., 1980.

\section{Foot Notes}

(1) People do not wear their shoes inside a Japanese house.

(2) The word in the original Japanese text is kimaru which is an intransitive verb. The closest expression in English may be "... be decided." It is not hard to imagine that the word kimaru can be used with no reference to the decision maker whatsoever. Readers who have read this paper to the end should be able to guess why such a word has broad usage in the Japanese language.

(3) The word $k u k u$ in Japanese means nine-nine (nine times nine). Unlike the popular $\mathrm{ABC}$ song, the $k u k u$ song is a rhythmic but a rather monotonic repetition of multiplication from $1 \times 1$ up to $9 \times 9$ (and back down to $1 \times 1$ ).

\section{Appendix}

A series of the theoretical research for the "Decision Moderatry Model" written by Eizo Kinoshita and Masatake Nakanishi is as follows.

(1) Eizo Kinoshita and Masatake Nakanishi: A proposal of a new viewpoint in analytic hierarchy process. Journal of Infrastructure Planning and Management, IV-36-569 (July 1997), p.1-8.

(2) Eizo Kinoshita and Masatake Nakanishi: A proposal of "concurrent convergence" as a processing technique for additional data in the dominant alternatives method. Journal of Infrastructure Planning and Management, IV-42-611 (January 1999), p.13-19

(3) Eizo Kinoshita: The development process and various problems about the AHP. Communications of the Operations Research Society of Japan, Vol.44 no.1 (January 1999), p.8-12

(4) Eizo Kinoshita and Masatake Nakanishi: Proposal of new AHP model in light of dominant relationship among alternatives. Journal of the Operations Research Society of Japan, Vol.42 no.2 (June 1999), p.180-197

(5) Eizo Kinoshita and Masatake Nakanishi: Proposal of Comparison Structure Analysis method (CSA). Journal of the Operations Research of Japan, (will be published in the future). 